\title{
THE USE OF ICT IN THE DIDACTIC PROCESS OF STUDENTS' EDUCATION
}

\author{
Michał Cupial \\ Anna Szeląg-Sikora \\ Maciej Kuboń \\ University of Agriculture in Krakow, Poland
}

\begin{abstract}
The modern education process requires introduction of modern information and communication technologies (ICT) in order to make classes more attractive, to properly implement curricular content and, as a consequence, to provide students with education compliant with applicable standards. Some didactic classes are more predisposed to the use of ICT, and others to a lesser extent. The Faculty of Production and Power Engineering of the University of Agriculture in Krakow has been using modern IT solutions to support the teaching process for many years. The mentioned ICT tools include the e-learning platform Moodle, office packages (Microsoft Office, Open Office), groupware tools, Internet platform Google Apps, Microsoft IT Academy and many specialized software. This study presents a case study of the use of ICT tools during selected subjects at the faculty.
\end{abstract}

Keywords: ITC, e-learning platform, didactic, education.

\section{Introduction}

At present it is not possible to teach in a modern way with no support of the cutting-edge technology, which not only accelerates the process of acquiring knowledge, but also makes it more effective and productive. The most important modern techniques and technologies applied in the teaching process include information and communication technologies (ICT). Information and communication technologies include all activities related to the production and use of telecommunications and IT (information technologies) devices, and services accompanying them, as well as to collecting, processing, sharing information in electronic form using digital techniques and all electronic communication tools (Stevenson, 1997).

Among the software supporting the didactic process in higher education, one can name Internet browsers, office packages, instant messengers, specialized software appropriate for the lessons, software supporting group work, and above all, the e-learning platforms (Grooms, 2018).

Distance learning is a technique which uses all available electronic media, namely: the Internet, satellite broadcasting, video, interactive TV, etc. However, 
as a rule the computer is currently responsible for the transfer of knowledge and examination thereof (Bates, 2014). Consequently, the center of gravity in teaching has been transferred from the teacher to the student (Liebowitz \& Frank, 2016, Uskov et al., 2015).

Distance learning is widely applied not only in education (Fallon \& Brown, 2016). It became very popular while training HR departments of enterprises and institutions, mainly due to the cost reduction of raising qualifications as well as the opportunity to complete the knowledge of people located in various places around the world (Cupiał et al., 2017, Kuboń \& Krasnodębski 2010, Wyslocka, 2015). Many companies create e-learning courses, thus giving the opportunity to acquire knowledge to people who would not be able to participate in the training in its traditional form. Such courses are usually developed as a single event and subsequently made repeatedly available to their recipients. The tools offered by the e-learning platforms are also applied in order to conduct exams, both remotely and under controlled conditions - in computer laboratories. The last example of application combines the possibility of objective evaluation of the course participants with the possibility of automatic and instant evaluation, as well as recording results on the server.

Distance learning has several advantages however, it has its disadvantages as well (Arkorful \& Abaidoo, 2015). Among the advantages one can distinguish reduction of training costs, time saving opportunity, ability to administer the courses easily, quick and easy updating of the presented content, control over the education process and, above all, the opportunity to learn anywhere and at any time. The ease of archiving events occurring during the education process is quite crucial. The greatest disadvantage thereof is the reduced teacher-student interaction (lack of personal contact) and the requirement of the student to have strong internal motivation and self-discipline. As far as the course organizer is concerned, a large initial workload and extensive costs associated with commissioning the course and the fact that not every training can be conducted without the personal contact demonstrate the greatest disadvantages.

Software supporting distance learning can be based on cloud computing solutions or be installed on the servers of the training organization. Among a number of available tools, commercial and free of charge solutions, usually distributed under Open Source licenses might be distinguished. One of the most popular platforms is Moodle (Futa \& Gocłowska, 2015), which is a free of charge solution available at moodle.org. A large community using the platform guarantees that the problems arising during operation will be solved. The Moodle platform is very flexible, easy to use, safe and above all - is free of charge. It has been widely used by schools, universities and companies since its development in 2002. Currently, the project is being built by a large team and is regularly updated. Moodle is equipped with such features as a gradebook, calendar and modules 
which make it possible to verify the knowledge and upload files in a quick way. Therefore, the system is one of the most frequently installed solutions of this type all over the world.

\section{Material and method}

The Faculty of Production and Power Engineering has been using the Moodle e-learning platform to support the teaching process for many years. They adopted the principle that the e-learning platform is supposed to support contact classes with students, and not replace them entirely (Cupiał Szeląg-Sikora, 2011). As a consequence, platform mechanisms complete the traditional form of education, which allows the best results. The Moodle platform is applied mainly for posting teaching materials, completing tasks, checking messages using tests, and communication between teachers and students. The platform is available at http://student.wipie.ur.krakow.pl, and each students has his/her own account.

Apart from the e-learning platform, the teaching process is supported by many applications, some of which can be regarded as applications supporting distance learning. Moreover, students use applications and services facilitating the process of studying, which might include the USSOS support system of studies. Students during their studies have their accounts on the Google platform set up that make it possible to use the groupware tools, e-mail account, online documents, calendar, disc, etc. The system of remote work also provides access to Microsoft's cloud tools, including Office 365, as well as many other programs and systems available within Microsoft IT Academy.

This study analyzes two courses which were conducted at the faculty in the specialty of Production Engineering and Management. The classes conducted in the first year (the first semester) and the fourth year (the seventh semester) in the form of full-time and weekend studies were compared herein. In the first year the subject was called "Information Technology" and in the fourth "Information Systems in Production Management”. Both the first and the second subjects regarded IT issues and were conducted in the computer laboratory. As part of the exercises, the students prepared some projects after the lessons. During the classes in the computer laboratory, students were obliged to perform some of the tasks using the e-learning platform, most of the work at home was an optional (not obligatory) work for the student.

The study covered the period from January 2015 to December 2017. The analysis included a total number of 10 courses:

- 2 course editions of full time studies in the first year,

- 2 course editions of weekend studies in the first year,

- 3 course editions of full time studies in the fourth year, 
- 3 course editions of weekend studies in the fourth year.

The user activity on the e-learning platform obtained from the Moodle system logs was subject to the analysis. The graphs show the activity of individual users, which was measured (recorded) by the activities registered by the system, such as e.g. opening a document with didactic materials, sending a task (attaching a file), verifying the grades or completing a test (quiz). The numbers to be found on vertical axes indicate the number of actions performed by the people using the platform. The numbers on scales indicate thousands of performed actions ( 1 on the scale corresponds to 1,000 activities).

A total number exceeding 69,000 activities was registered, 35,000 of which refer to the first-year students of full-time studies, 13,000 - the first-year students of weekend studies, 15,000 - the fourth-year students of full-time studies, 6,000 the fourth-year students of weekend studies.

\section{Results}

Each drawing includes two graphs: the left hand side is dedicated to full-time studies, and the right hand side to weekend studies. The activity of students was divided into work during the lessons and using the e-learning platform at home (outside the university). The criterion for separating the activity was the IP address from which the students performed particular activities.
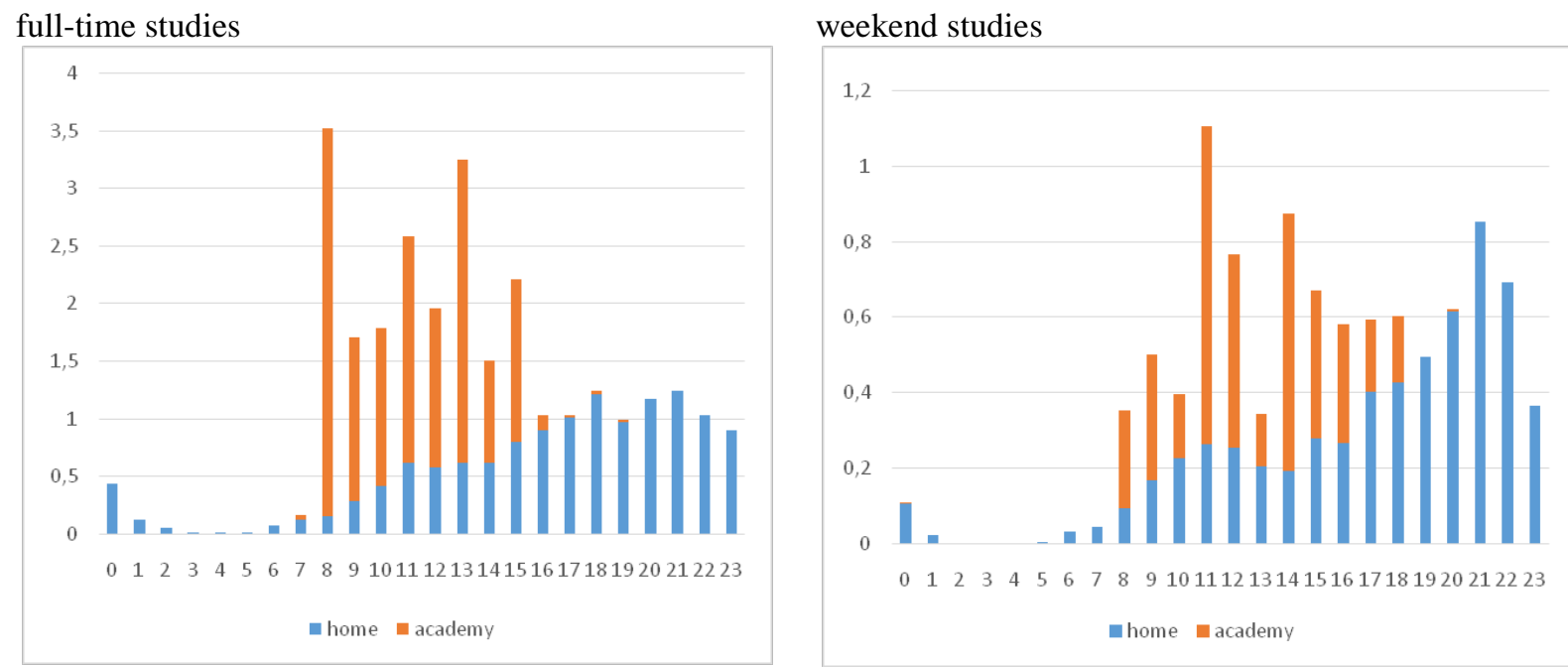

Fig. 1. The activity of the first-year students on the e-learning platform during all hours of the day

Fig. 1 shows the daily distribution of engagement of the first-year students on the Moodle platform. At full-time studies, the students started classes at 8 a.m. and some groups finished at 8 p.m.. Therefore, it can be seen that some students 
appeared in the computer laboratory before the scheduled beginning of the lesson. Uneven distribution of the activity during the classes results from different lessons in the subsequent years, and different group sizes. The time when students work independently (outside the university) should be stressed as well. It is as much as $48 \%$ of the total activity of the course and takes place from the early morning hours to late night hours. The students work most intensively during the night hours (until midnight), and in many cases they work after coming back home (or to the place of residence) from university. The daily schedule at weekend studies is slightly different. Because of fewer students and active hours, the level of engagement is also lower. In this case, the activity at home gradually increases during the day and reaches its maximum value at 9 p.m.. In the case of weekend studies, the activity outside the university is as much as $60 \%$. This proves that people at weekend studies dedicate more time to their individual work in order to obtain appropriate knowledge and skills.

Fig. 2 shows the daily activity of the fourth-year students on the e-learning platform. Taking account of different specificity of the subject, the use of the elearning platform was less intensive. In this case, the students conducted the major part of the project during the exercises, which is manifested by a high proportion of engagement during the lesson and is applicable to both modes of studies. As part of these lessons, $25 \%$ of the students of full-time studies and $16 \%$ of the students of weekend studies were engaged in the activities outside the university. In this case, the activity after the exercises at the university is distributed rather evenly starting from the morning hours to slightly after midnight.
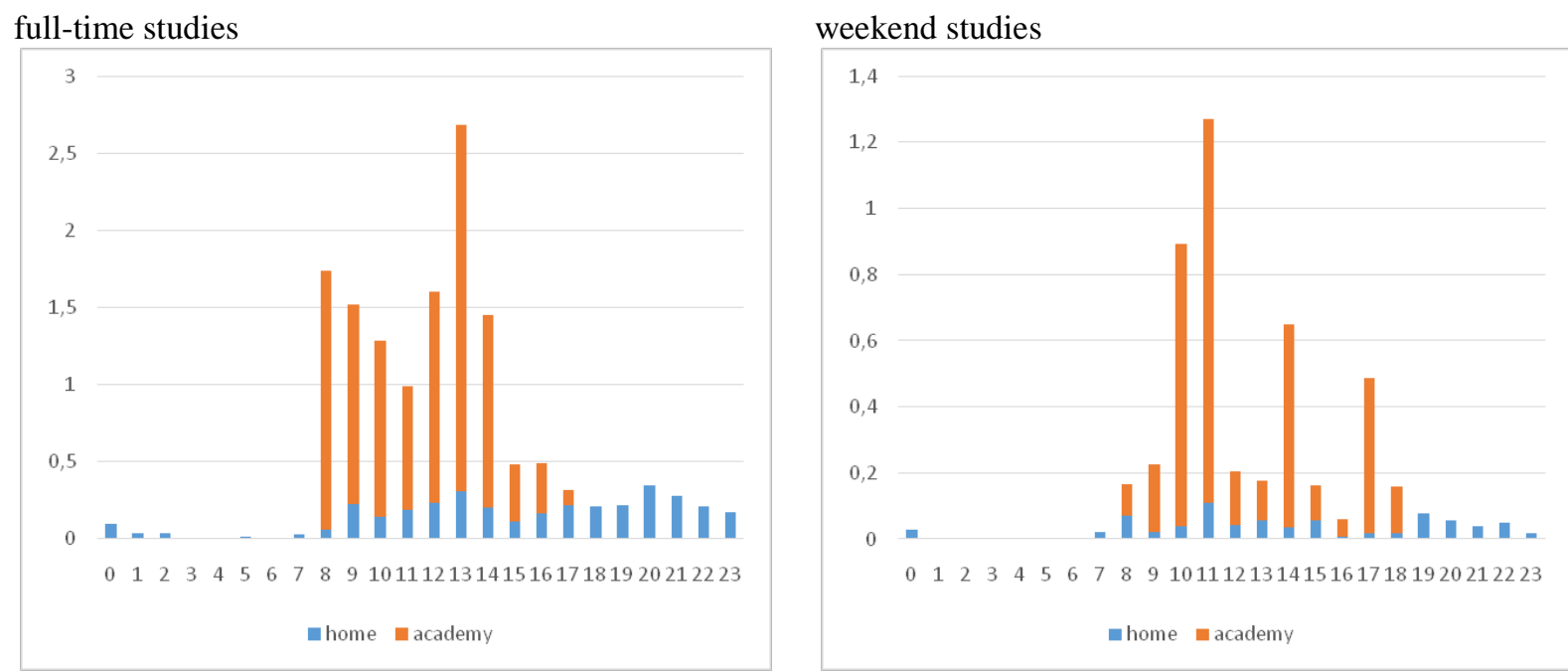

Fig. 2. The activity of the fourth-year students on the e-learning platform during all hours of the day 
Fig. 3 shows the weekly activity of the first-year students. The graphs clearly show the days, when the classes were conducted in the computer laboratory, i.e. Monday, Tuesday and Thursday at full-time studies, and Saturday and Sunday at part-time studies. In the latter case, one can notice slight engagement on other days of the week, which was a result of additional hours of consultation provided for these students. It is interesting that in the case of the students of weekend studies, their activity covered all days of the week, and its greatest intensity was observed in the middle of the week. The students of full time studies also worked outside the university throughout the week, namely on Sunday and Monday in the most intensive way.
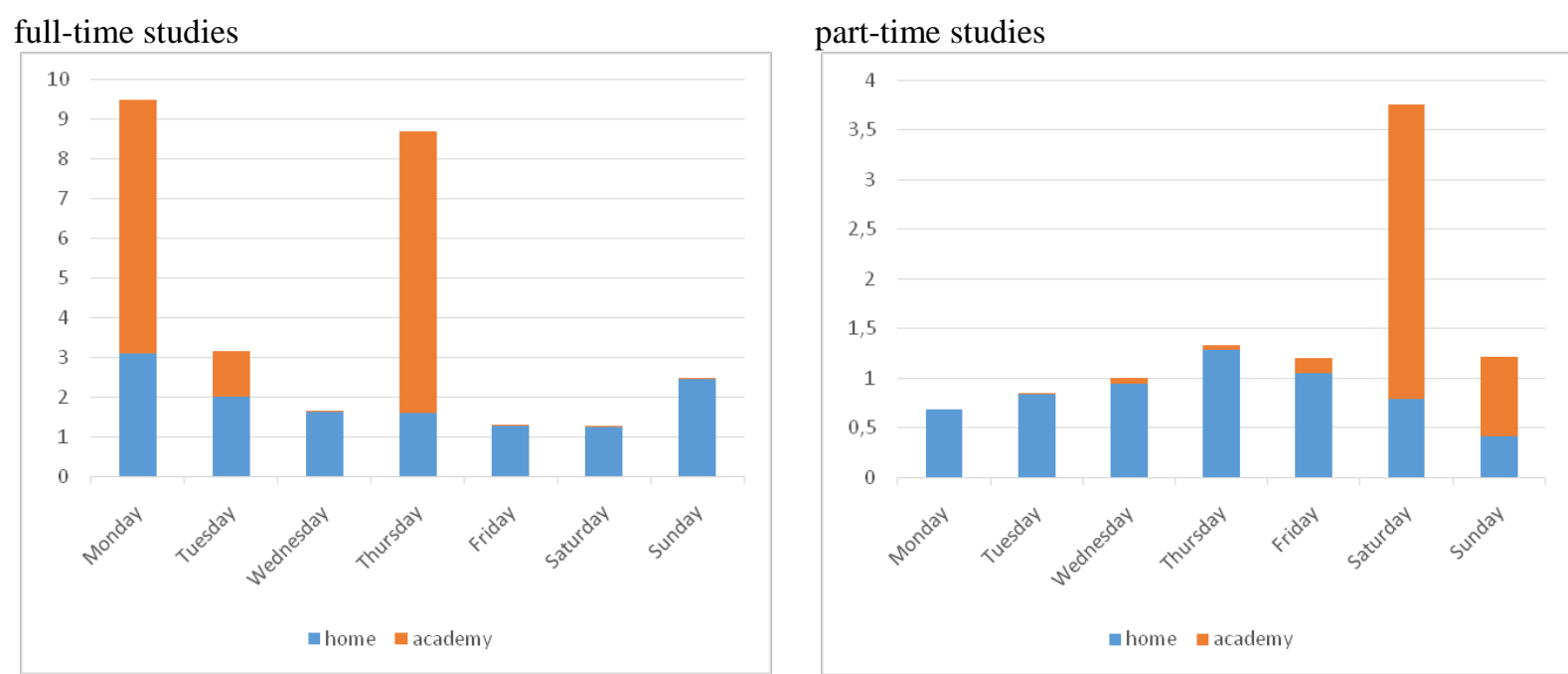

Fig. 3. The activity of the first-year students on the e-learning platform on weekdays
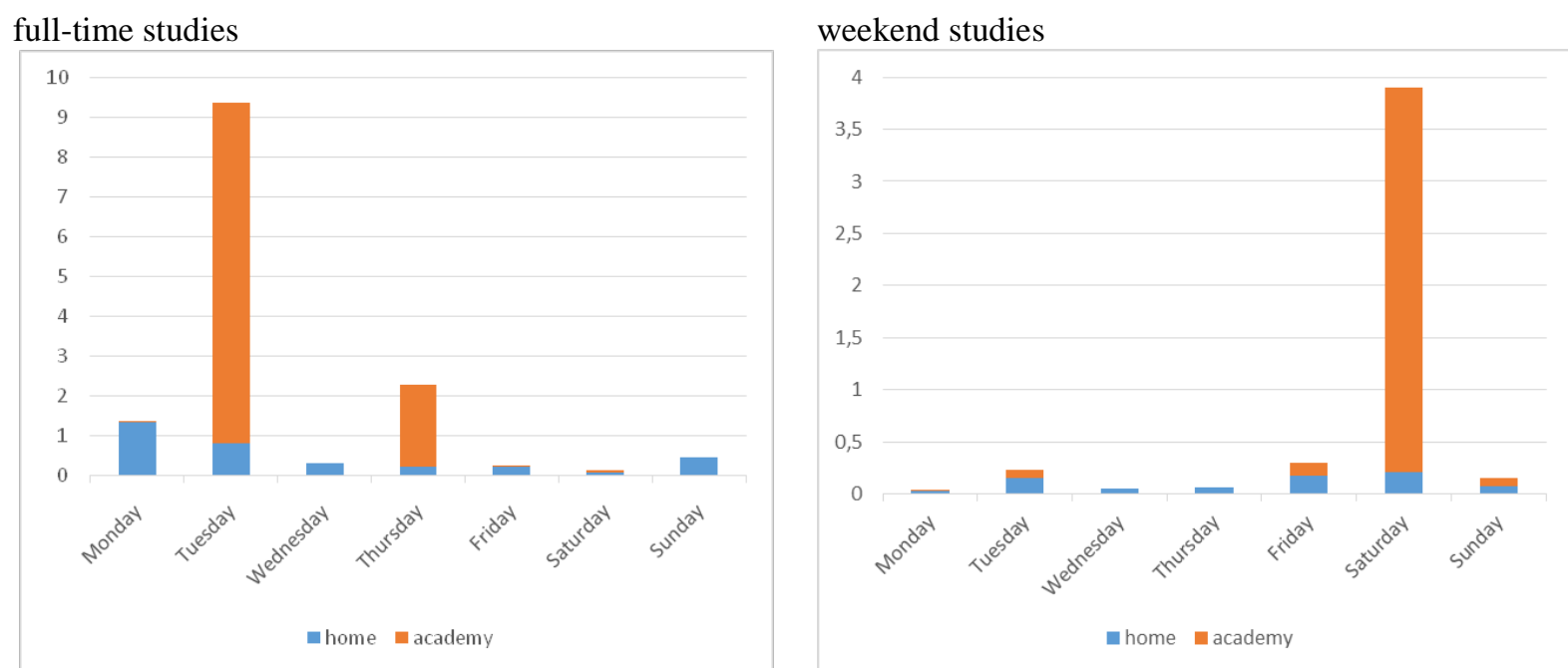

Fig. 4. The activity of the fourth-year students on the e-learning platform on weekdays 
The distribution of the weekly activity of the fourth-year students is illustrated in Fig. 4. The classes were held on Tuesday and Thursday on full-time studies, and on Saturday on weekend studies. In this case, the students demonstrated the greatest engagement on the days preceding the classes, which might be explained by the preparation for the classes at the university.

Fig. 5 and 6 present the daily activity of the course participants divided into the category of platform users. The relatively high engagement of teachers denies the opinion that in the case of the e-learning platform, the role of the teacher may be marginalized. Their activity (together with the course administrator) in the first year amounted to $20 \%$ of all activities performed at full-time studies and as much as $23 \%$ on weekend studies. In the case of the fourth year, it was $7 \%$ and $16 \%$, respectively.
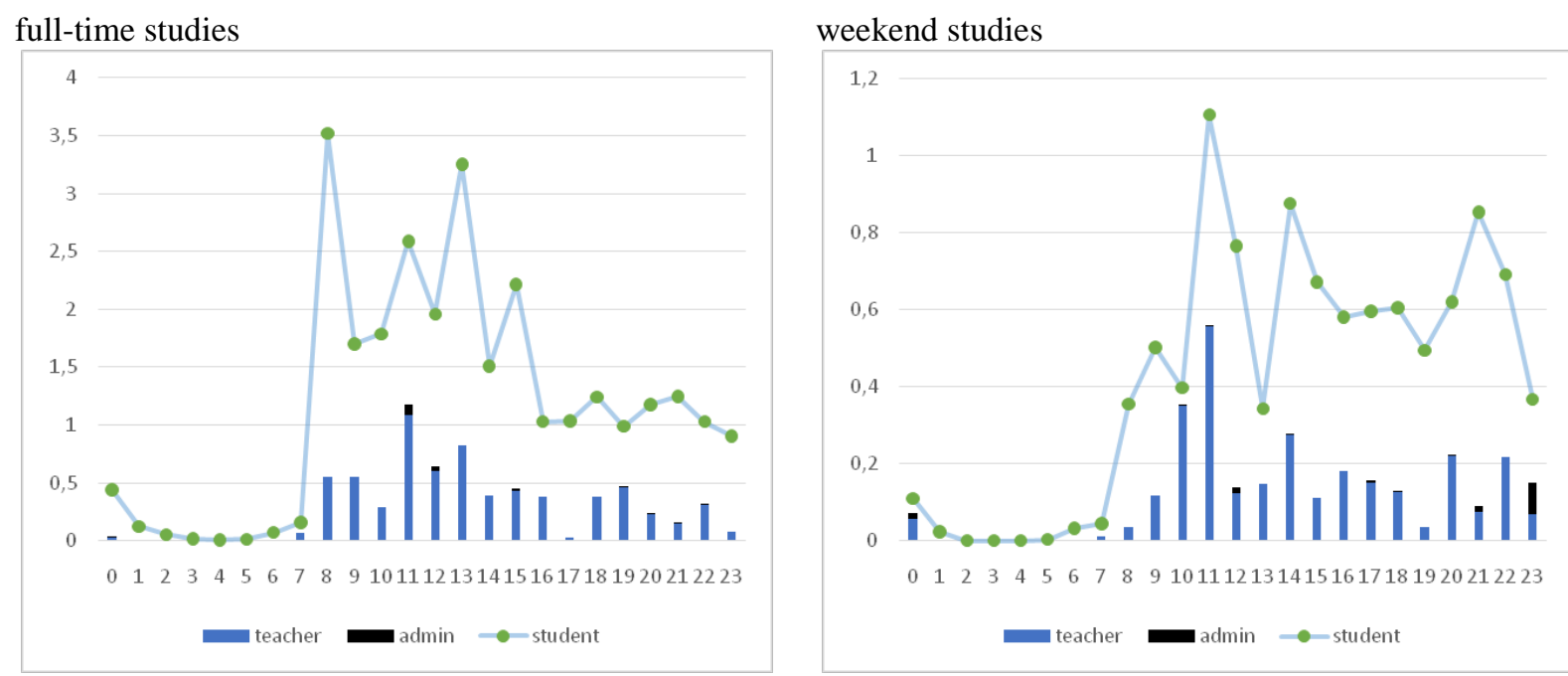

Fig. 5. The activity of the teachers of the first year on the e-learning platform during all hours of the day

It seems that despite a smaller number of hours on weekend studies, the participation of teachers is much greater than in the case of full-time studies. It might be confirmed that the working hours of the teacher encompass both the time dedicated to conducting the lesson and the time not recorded in the working hours. On the basis of the analysis of the activity on the e-learning platform, it might be clearly noticed that this time constitutes a great percentage in the working hours of the teacher. Apart from providing the lessons on a regular basis, the teacher prepares didactic materials and makes them available to students, checks the tasks delivered by the students and evaluates them, introducing the grades into the system, and uses the Moodle mechanisms for communication purposes.

Certainly, it is possible to create entirely maintenance-free courses on the elearning platform. However, the interaction between the teacher and the student 
significantly increases effectiveness of teaching, even if it is conducted with the use of remote tools. An additional factor increasing the workload of the teacher is the specificity of the lessons the teacher conducts. The didactic classes subject to analysis contain education content that changes very quickly (as it refers to modern techniques and technologies). As a consequence, it is not possible to create a single course and copy it in the same form in subsequent years.
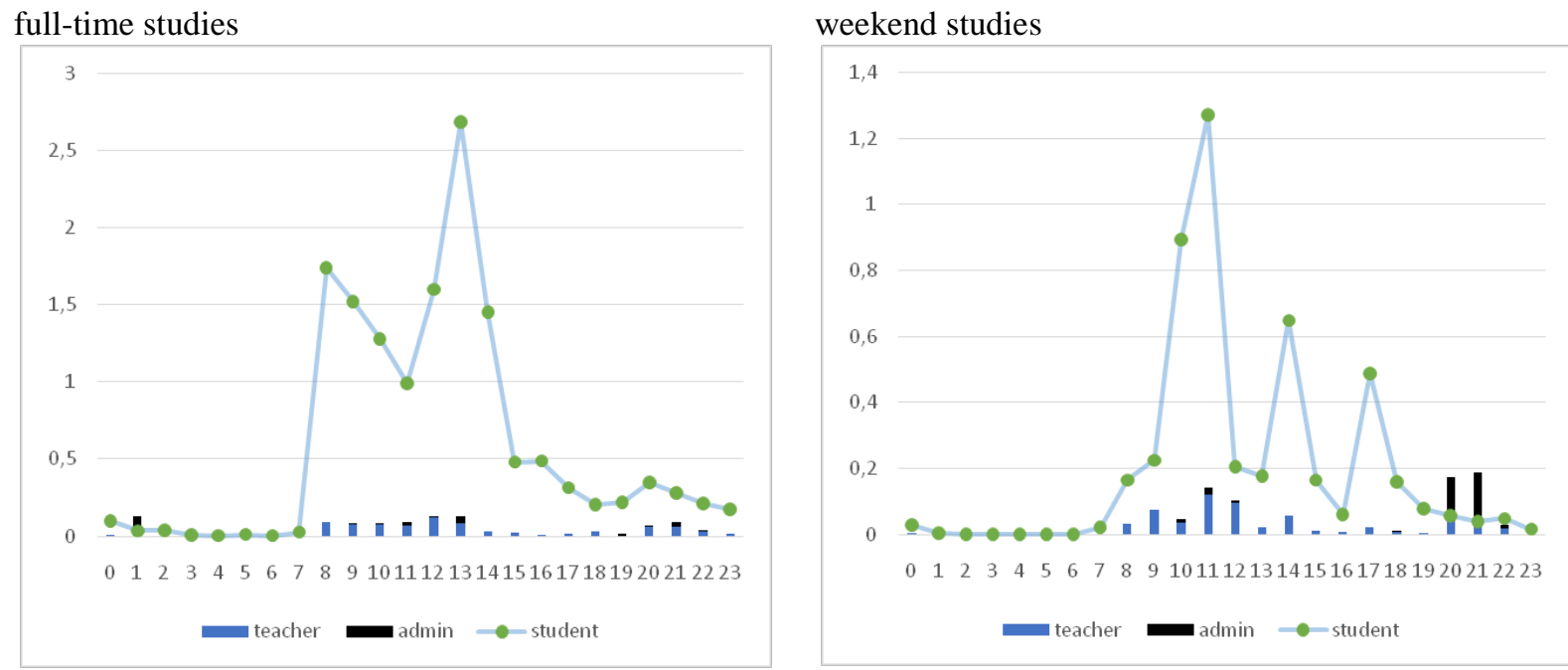

Fig. 6. The activity of the teachers of the fourth year on the e-learning platform during all hours of the day

While running the lessons with the use of the Moodle platform in recent years, the following phenomenon was observed. Some students downloaded didactic materials from the platform and subsequently shared them with colleagues via the social networking site - Facebook. As far as the mechanisms of the e-learning platform are concerned, this situation seems unfavorable, as one of the benefits of using this tool is the control over the downloaded content, and transferring documents using other tools is not recommended. However, due to great popularity of Facebook among students (currently $100 \%$ of the surveyed students at the faculty are active users thereof), it is used to support many activities, even if it is not an optimal solution. As a results of the intensification of this phenomenon, distance learning must be taken into account in the shortterm future. It should be noted that the Moodle platform applied at the Faculty of Production and Power Engineering is equipped with mechanisms integrating it with selected portals and social websites (e.g. Facebook), and the student accounts used in Moodle are integrated with Google accounts. 
SOCIETY. INTEGRATION. EDUCATION

Proceedings of the International Scientific Conference. Volume V, May $25^{\text {th }}-26^{\text {th }}, 2018.238-247$

\section{Conclusion}

The analysis of the activity of the students on the e-learning platform at the Faculty of Production and Power Engineering has demonstrated that the students actively use this tool both during the exercises in the computer laboratory and outside the university. Significant engagement is noticed during the evening and night hours. One can observe the diversity in the activity of the platform users in different years of studies and during various subjects. The list of system logs of the platform demonstrated high activity of teachers conducting classes, which applies to both the teaching hours and the time dedicated by them to provide the courses. It might be concluded that the time saved thanks to the mechanisms that enable automatic verification of quizzes is later dedicated to preparing teaching materials suitable for distance learning. Preparation of such materials is usually more difficult than developing teaching aids in a traditional form.

Distance learning is constantly developing and adapting to modern techniques and technologies. These changes result from the necessity to provide students with knowledge and skills in the best available form. Changes in the mentality and way of life of the recipients of the teaching process necessitate searching for new tools supporting the transfer of knowledge. The best didactic effects are achieved when elements of traditional teaching (interaction with the teacher) are combined with the possibilities of modern e-learning platforms (selfstudy).

\section{References}

Arkorful, V., \& Abaidoo, N. (2015). The role of e-learning, advantages and disadvantages of its adoption in higher education. International Journal of Instructional Technology and Distance Learning, 12 (1), 29-42.

Bates, T. (2014). The Role of Technology in Distance Education (Routledge Revivals). Routledge.

Cupiał, M., \& Szeląg-Sikora, A. (2011). Wykorzystanie technologii informacyjnych w procesie kształcenia na Wydziale Inżynierii Produkcji i Energetyki Uniwersytetu Rolniczego w Krakowie. Nauka i Gospodarka w dobie destabilizacji, Biuro Projektu Nauka i Gospodarka.

Cupiał, M., Szeląg-Sikora, A., Sikora, J., Rorat, J., \& Niemiec, M. (2017). The use of IT tools for knowledge management in companies, No. 20.

Fallon, C., \& Brown, S. (2016). E-learning standards: a guide to purchasing, developing, and deploying standards-conformant e-learning. CRC Press.

Futa, G., \& Gocłowska, B. (2015). Analysis of functionality of distance learning platform moodle. Annales Universitatis Mariae Curie-Sklodowska, sectio AI-Informatica, 3(1), 331-338.

Grooms, L. D. (2018). Distance Teaching and Learning Platforms. In Encyclopedia of Information Science and Technology, Fourth Edition (pp. 2455-2465). IGI Global. 
Kuboń, M., \& Krasnodębski, A. (2010). Logistic cost in competitive strategies of enterprises. Agricultural Economics. 56, 397-402.

Liebowitz, J., \& Frank, M. (Eds.). (2016). Knowledge management and e-learning. CRC press.

Stevenson, D. (1997). Information and communications technology in UK schools: An independent inquiry. London: Independent ICT in Schools Commission, 41.

Uskov, V. L., Howlett, R. J., \& Jain, L. C. (Eds.). (2015). Smart education and smart e-learning, Vol. 41. Springer.

Wyslocka, E. (2015). E-learning in the management of Polish companies. Polish Journal of Management Studies, 11, 188-199.

Zawacki-Richter, O., Müskens, W., Krause, U., Alturki, U., \& Aldraiweesh, A. (2015). Student media usage patterns and non-traditional learning in higher education. The International Review of Research in Open and Distributed Learning, 16(2). 